\title{
Radiative cooling in polish climatic conditions
}

\author{
Wojciech Cepiński ${ }^{1, *}$, Bartosz Szmigiero ${ }^{1}$ \\ ${ }^{1}$ Wrocław University of Science and Technology, Faculty of Environmental Engineering, Department \\ of Air Conditioning, Heating, Gas Engineering and Air Protection, \\ 4/6 Norwida st., 50-373 Wrocław, Poland
}

\begin{abstract}
Ecological, natural ways of obtaining energy for building cooling are becoming more and more popular around the world. Reducing energy demand and increasing the renewable energy use can be achieved for example by using radiative cooling. Depending on climatic conditions and the type of cooling system, radiative cooling is able to cover a part of refrigeration needs. The document presents the possible energy yield from using radiative cooling in systems operating at respective parameters in polish climatic conditions.
\end{abstract}

\section{Introduction}

The inevitable need of preserving energy and the necessity to limit air pollution requires taking advantage of solutions which favor using free natural energy. Moreover, changes in the energy sector became obligatory due to the directives made by the EU parliament.

In climate zone typical for Poland forming the micro-climate of interiors requires heating them for a long time, but more and more often also to cool them. This consumes almost $40 \%$ of state produced energy. Acquiring cheap and "green" energy from natural sources may meet or supplement the energetic needs of buildings, lowering the need for producing fossil fuel energy.

The term natural energy is understood as commonly available natural energy sources which may be acquired and used for a specific purpose. In theory, the natural environment offers unlimited energy sources. The basic obstacle concerning using that energy for heating and cooling purposes consists in its low density and reverse proportion in terms of availability and demand. Cold, easily accessible in nature during wintertime, is needed in buildings during the summer and natural heat available in the summer time is needed in buildings during the winter.

Due to the increasing requirements concerning the comfort and accessibility of technology, cooling building becomes more and more common. Apart from heating, cooling becomes a significant element of the year-long energy demand for buildings. Natural energy may constitute the source of cold also during the summer time, because there are technologies for acquiring useful cold from the environment even in the middle of the summer. One of such methods is taking advantage of the radiative cooling effect as a cheap and natural source of energy for cooling buildings.

\footnotetext{
${ }^{*}$ Corresponding author: wojciech.cepinski@pwr.edu.pl
} 


\subsection{Radiative cooling [1-2]}

The phenomenon of radiative cooling consists in lowering the temperature of a given body below the temperature of the surrounding air due to radiating the heat into the cooler atmosphere. The most intense radiative cooling concerns horizontal surfaces (flat roofs, grounds, etc.). The strongest radiative cooling takes place during the night in the conditions of a cloudless sky, because that is when the least atmospheric skyward radiation reaches the horizontal surface, constituting a compensation for the heat emanation of that surface. Due to the significant radiative heat losses, the temperature of the external surface of a given radiator (flat roof, ground, etc.) may decrease in reference to the surrounding temperature at 4 to $7^{\circ} \mathrm{C}$, and in favorable conditions even at $11^{\circ} \mathrm{C}$. The cloud cover of the sky limits radiative cooling, which has been shown in fig. 1. In analogical thermal conditions and at a full, partial, and zero cloud cover, various temperatures of skyward heat radiation surfaces are achieved.

From the collecting cold point of view in the natural process of radiative cooling, cloudless nights with a clear sky are desirable.

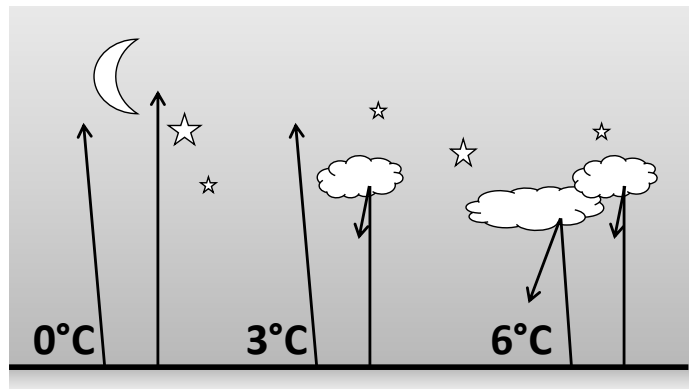

Fig.1. Radiative cooling - the mechanism of the phenomenon.

Radiative cooling constitutes a passive method of acquiring cold for cooling buildings. It is the opposite of the popular mechanism of collecting heat from solar radiation with solar collectors (fig. 2).
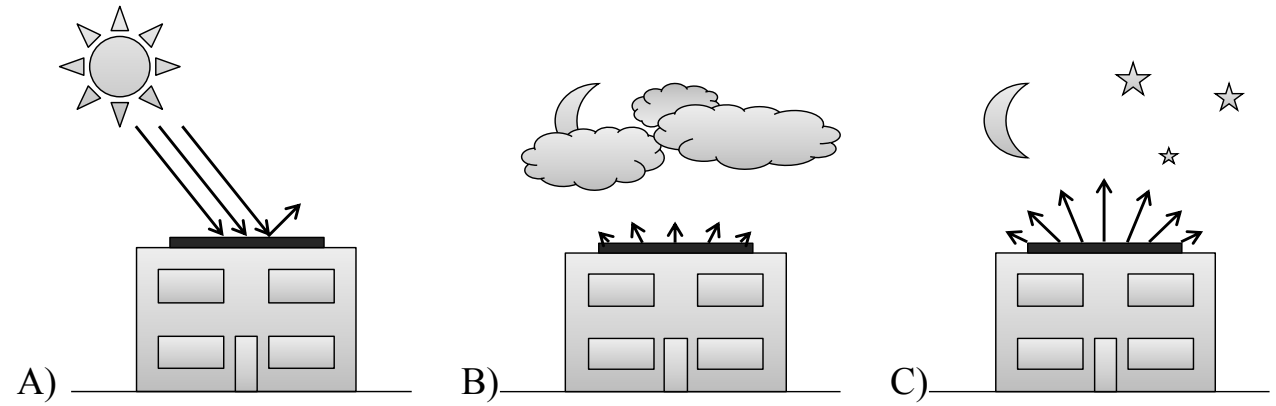

Fig. 2. Passive sunlight heating (A) and passive radiative cooling in cloudy (B) and cloudless (C) sky conditions.

The effect of passive radiative cooling has been known for ages. Already in ancient times and in countries with a warm climate, buildings were erected in a manner taking advantage of radiative cooling in order to cool down the interiors during the night, which were heated during the day. It was also used to manufacture ice at the desert. In Poland 
effects of radiative cooling may be observed for example: in a layer of frost created on the surface of a car window at the conditions of a cloudless sky and temperatures above zero, or the so called radiative mist appearing at dusk due to the heat radiation taking place at night.

In terms of the cooling technique, innovative constructions are being created, successfully taking advantage of the radiative cooling effect. Special nano-optic materials reflect solar radiation at the same time radiating heat to the open sky, lowering the temperature of the surface they are mounted on, for example a roof [3-5].

The goal of radiative cooling is to take full advantage of the potential coming from climate and weather conditions. In such a solution a portion of the energy required to lower the temperature of the cooling agent, which in the basic variation consists in the work of a compressor, becomes exchanged for energy provided in a direct manner (radiative cooling panel), excluding or limiting the work of a compressor cycle. Using radiative cooling results in an increase in the energetic efficiency of the process of cooling water for the purposes of cooling interiors, as well as reducing the costs of that process, due to limiting the energy consumption needed for the functioning of the refrigerating unit.

Radiative cooling may be successfully used in office buildings, commercial, housing, and industrial facilities. However the factor impacting the potential of using it consists in the temperature of the water agent powering the installation. The lower that temperature is the lower the potential of using radiative cooling.

\section{Analysis}

There are many solutions for installations and systems used to cool down buildings, in which water constitutes the refrigerant. Depending on the assumed solution the operating temperatures of the recirculating water change, as do the type and size of the interior cold receiver. Low operating temperatures of circulating water (for example $12 / 16^{\circ} \mathrm{C}$ ) allow to limit the size of the receiver and increase its efficiency however, require a very efficient source of cold. Average temperatures (for example $14 / 18^{\circ} \mathrm{C}$ ) increase the necessary surface of the cold receiver, at the same time allowing to take advantage of more energy-efficient sources of cold. Higher temperatures of circulating water (for example $16 / 20^{\circ} \mathrm{C}$ ) require large cooling surfaces in interiors, at the same time allowing to take advantage of natural sources of cold with a low density heat flux. In some buildings with moderate requirements concerning the temperature of cooled interiors, it is possible to find cooling systems with relatively high parameters (for example $18 / 22^{\circ} \mathrm{C}$ ), taking advantage of cooling surfaces which in the winter time constitute heating surfaces (floors, walls). During heat waves this constitutes a significant relief for the users and does not require additional investments in a complex system of active cooling.

\subsection{Assumptions}

The analysis assumed a water, two-pipe, pump cooling system powered by a conventional electricity-powered compressor source of cold, for typical ranges of circulating water temperatures.

Taking advantage of statistical climate data available on the website of the Ministry of Infrastructure and Construction [6], the variations of external conditions for 61 weather stations located all over the country were analyzed in an hourly manner in terms of the possibility to take full or partial advantage of radiative cooling for the radiative production of cold at the size of the radiative panel at $1 \mathrm{~m}^{2}$ and its efficiency at $90 \%$. 
The analysis concerned only the potential resulting from weather conditions and did not include the possibility to provide the required amount of energy or selecting devices for a specific solution.

Two cases of the system's operation have been assumed, meaning year-long, and seasonal (between months V and IX) operation. Furthermore, four variations of the system's operation have been assumed for the following parameters of the refrigerant $-12 / 16^{\circ} \mathrm{C}$, $14 / 18^{\circ} \mathrm{C}, 16 / 20^{\circ} \mathrm{C}$, and $18 / 22^{\circ} \mathrm{C}$.

The accumulation of heat in a buffer tank charged in favorable periods, has been assumed. A system presented in Fig. 3 has been assumed for the purposes of the analysis.

The values of average sky radiation temperatures $t_{r}\left[{ }^{\circ} \mathrm{C}\right]$ in the entire range of the thermal radiation spectrum for the horizontal surface of Poland have been determined with the use of empirical formulas developed by Nowak [1-2]:

a) for the conditions of a cloudless sky:

$$
t_{r}=-19.04+1.33 \cdot t_{e}
$$

b) for the conditions of a completely clouded sky:

$$
\begin{gathered}
t_{r}=-0.92+1.14 \cdot t_{e} \\
\text { where } t_{e}-\text { air temperature, }\left[{ }^{\circ} \mathrm{C}\right]
\end{gathered}
$$

The radiation force has been determined basing on the dependency:

$$
\mathrm{Q}=\mathrm{A} \cdot \mathrm{e} \cdot \sigma \cdot\left(\mathrm{T}_{1}^{4}-\mathrm{T}_{2}{ }^{4}\right)
$$

where A- panel surface $\left[\mathrm{m}^{2}\right]$, e - emissivity, $\sigma$ - Stefan-Boltzmann constant

$\left[\mathrm{W} /\left(\mathrm{m}^{2} \cdot \mathrm{K}^{4}\right)\right], \mathrm{T}-$ temperature $[\mathrm{K}]$.

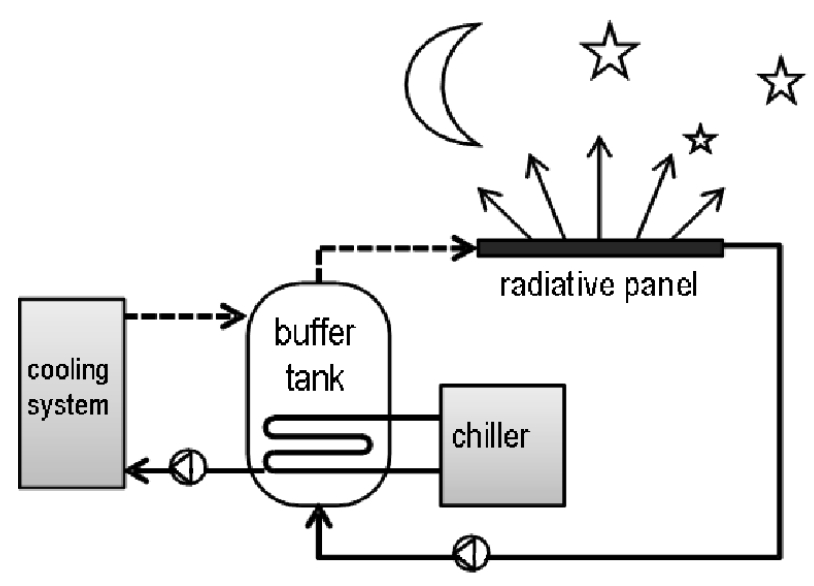

Fig.3. The plan of a system for collecting cold from radiative cooling.

\subsection{Results}

Fig. 4 and 5 present detailed results concerning the seasonal and year-long operation of systems and all analyzed variations for 61 Polish weather stations. Respective bars represent the production of natural cold and present the total yield of energy from a radiative panel in $\mathrm{kWh}$ for a given location in reference to the surface of $1 \mathrm{~m}^{2}$.

Presenting the results shows that it is possible to support a conventional building cooling system with the use of radiative panels (radiative cooling). For a given surface of radiative panels an increase in the share of natural cold can be observed along with the increase of the temperature of circulating water within the cooling system. This means that a natural source of cold will be more efficient in supporting systems with a smaller 
difference between the temperatures of circulating water and its surrounding, meaning ones which require a thermal flux with a lower density. Correctly adjusting the surface of panels will allow to increase the share of natural cold in meeting the building's demand.

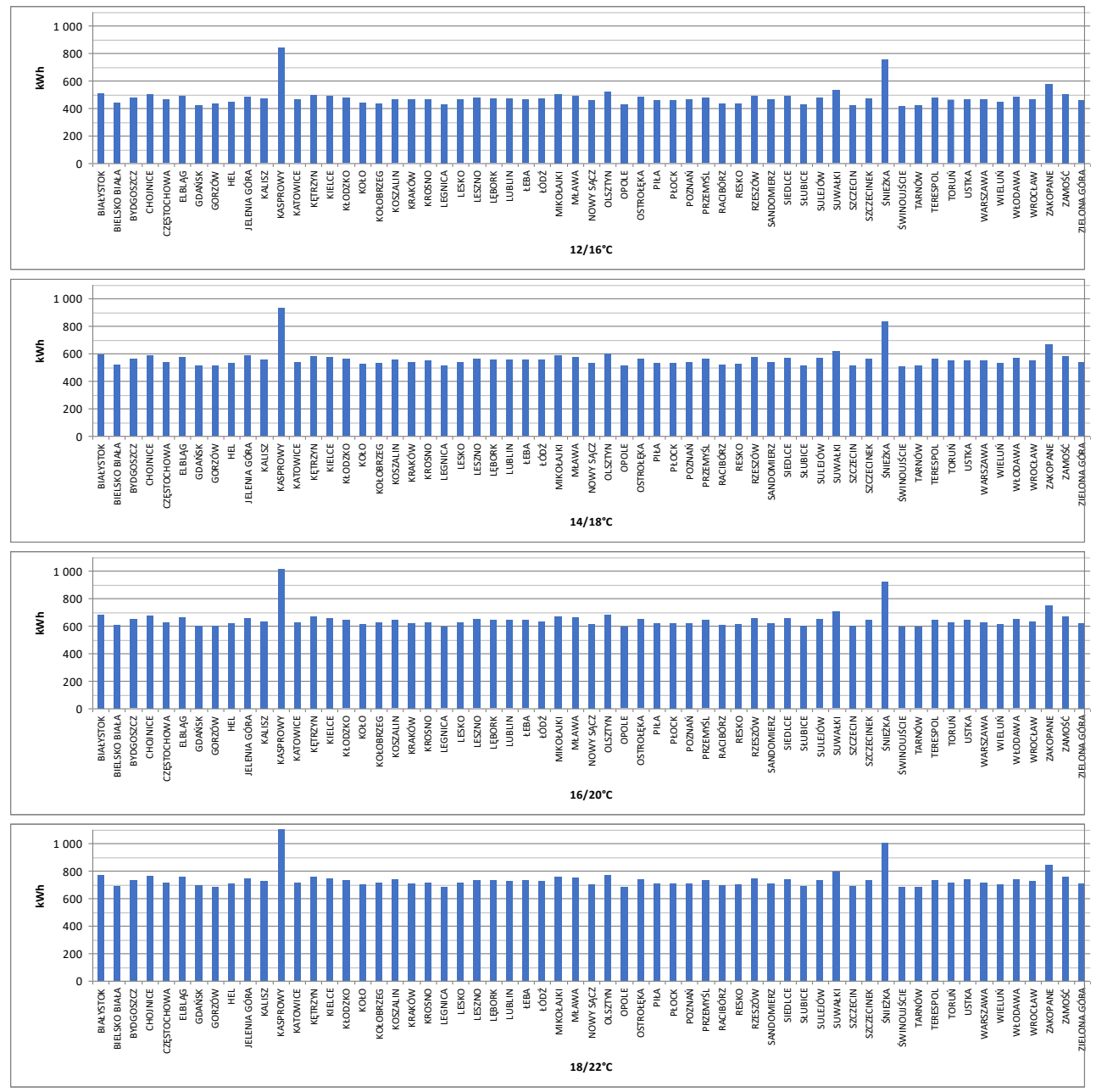

Fig.4. Total energy yield in $\mathrm{kWh}$ - year-long cycle in order: $12 / 16^{\circ} \mathrm{C}, 14 / 18^{\circ} \mathrm{C}, 16 / 20^{\circ} \mathrm{C}, 18 / 22^{\circ} \mathrm{C}$.

The conducted analysis presents that the average energy yield possible to be achieved from a $1 \mathrm{~m}^{2}$ radiative cooling surface in Poland is:

- for the refrigerant parameters at $12 / 16^{\circ} \mathrm{C}$ and a year-long operation - circa $468 \mathrm{kWh}$, and for its operation between $\mathrm{V}-\mathrm{IX}$ - circa $59 \mathrm{kWh}$,

- for the refrigerant parameters at $14 / 18^{\circ} \mathrm{C}$ and a year-long operation - circa $551 \mathrm{kWh}$, and for its operation between $\mathrm{V}-\mathrm{IX}$ - circa $91 \mathrm{kWh}$,

- for the refrigerant parameters at $16 / 20^{\circ} \mathrm{C}$ and a year-long operation - circa $639 \mathrm{kWh}$, and for its operation between V - IX - circa $128 \mathrm{kWh}$,

- for the refrigerant parameters at $18 / 22^{\circ} \mathrm{C}$ and a year-long operation - circa $728 \mathrm{kWh}$, and for its operation between V - IX - circa $166 \mathrm{kWh}$, 


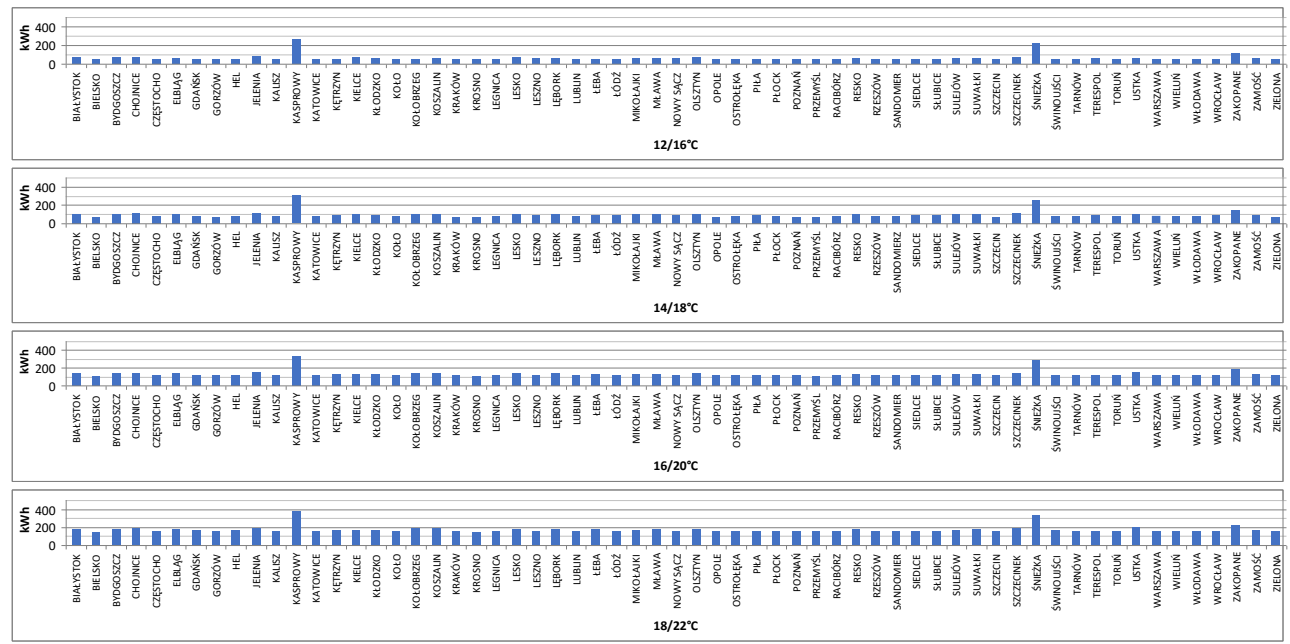

Fig.5. Total energy yield in $\mathrm{kWh}$ - seasonal cycle (between months V and IX) in order: $12 / 16^{\circ} \mathrm{C}$, $14 / 18^{\circ} \mathrm{C}, 16 / 20^{\circ} \mathrm{C}, 18 / 22^{\circ} \mathrm{C}$.
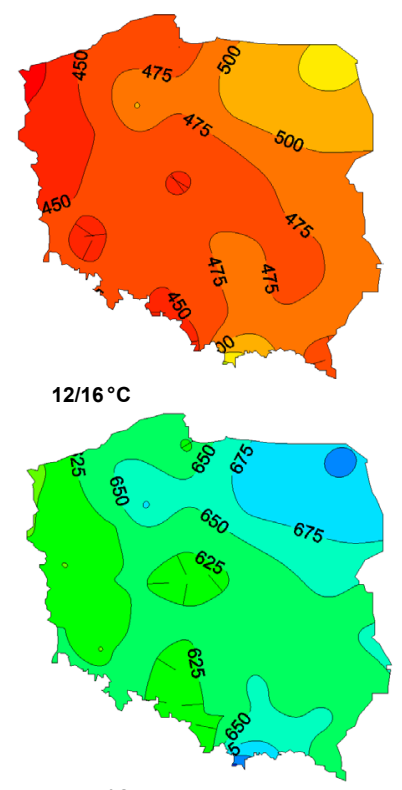

$16 / 20^{\circ} \mathrm{C}$

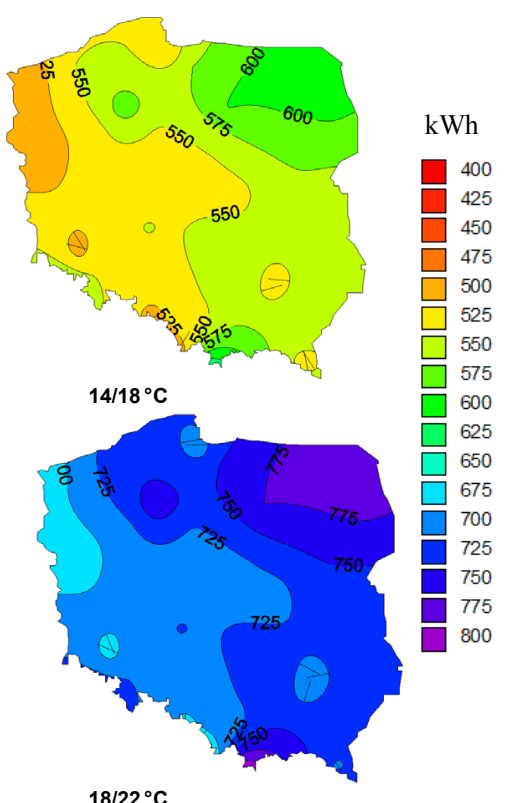

$18 / 22^{\circ} \mathrm{C}$

Fig.6. The production of natural cold from $\mathrm{m}^{2}$ of a radiative panel in $\mathrm{kWh}$ in Poland - year-long cycle

These are average results calculated for the entire Poland, excluding two mountain locations - Śnieżka and Kasprowy Wierch. These stations have been excluded because their impact on the results is significant while they are not representative for the entire country. They also do not constitute the typical locations of cooled facilities.

When it comes to discrepancies between specific regions of the country, they are not significant, apart from the excluded locations. The maximum difference reaches $14 \%$ for 
a year-long operation without taking into consideration the Zakopane weather station. Whereas, for seasonal operation this difference reaches 36\% excluding Zakopane.

Fig. 6 and 7 show maps of Poland presenting the possible energy yield from using radiative cooling in systems operating at respective parameters. As it can be seen the most privileged areas are located in the north-east part of the country, while the less advantageous ones west of Poland.
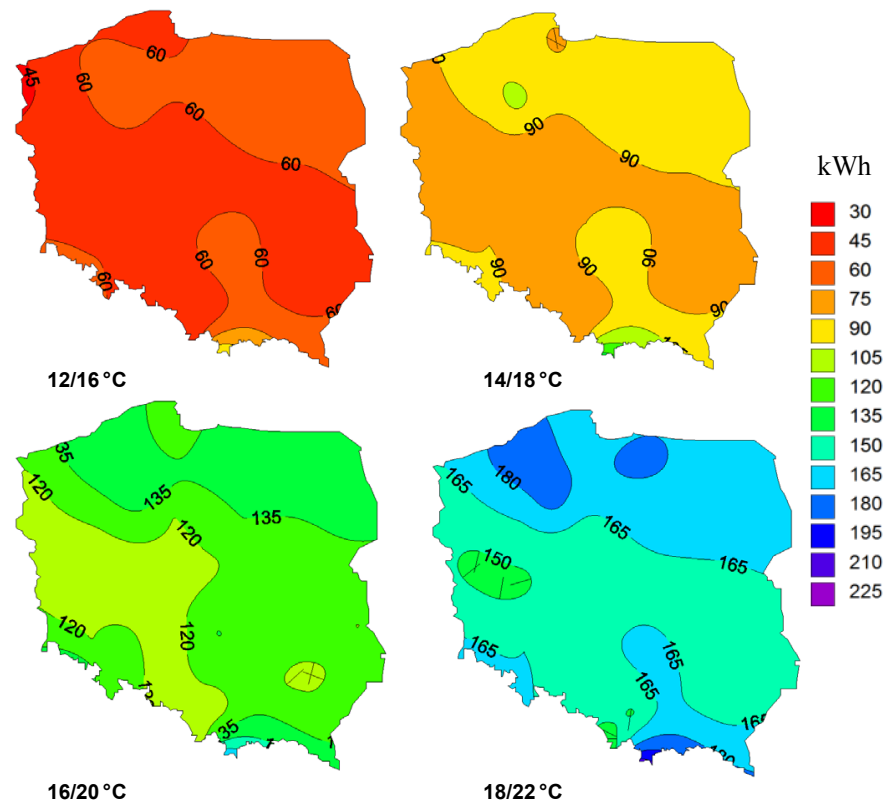

Fig.7. The production of natural cold from $\mathrm{m}^{2}$ of a radiative panel in $\mathrm{kWh}$ in Poland - seasonal cycle (between months V - IX).

\section{Conclusions}

Taking advantage of radiative cooling to support a compressor device is favorable for all parameters of the refrigerant in a year-long model of operating a cooling system, for example in interiors with an almost constant heat yield (for example internal server rooms). In terms of maintenance costs, a solution basing on the highest possible parameters of the system's operation will be the most advantageous.

The above analysis strongly questions the logic behind investing in radiative cooling systems for installations operating only during the hot season, especially with low and average parameters of the refrigerant. For an operation in the discussed seasonal mode, taking advantage of radiative cooling is justified only in case of the highest parameters of the cooling system's operation. In practice, this solution may find application mainly in systems operating with the use of cooling bars and surfaces, which are currently not very popular in our country.

The conducted analysis of the possibility to use free cooling for the purposes of preparing a refrigerant aimed to present the sensitivity of results in terms of external parameters and the cooling system's operating model. It has been indicated that taking 
advantage of a given solution in different regions of Poland and at various operating models should each time be preceded by a technical-economical analysis.

\section{Summary}

Recently any possibilities of acquiring free natural energy are becoming more popular. Various legal requirements of the European Union, a growing awareness, and a trend to save and respect energy, result in that every solution which improves the operating efficiency of cooling systems, should be taken into consideration at the planning, designing, and executing stages of any new project.

As it was shown by the above analysis, correctly used radiative cooling allows to limit the consumption of conventional energy in an environmentally friendly manner, while passive cooling (basing solely on radiative panels) is possible with extremely advantageous solutions such as for example zero-, or nearly zero-energy buildings. This requires to properly take advantage of the building's architectural aspects, a correct manner of accumulating and distributing cold in the building, and efficiently working with other passive solutions.

An interesting concept consists in combining a solar collector and a radiative panel in one surface. During the day the surface collects heat as a solar collector and produces cold at night, taking advantage of radiative cooling. Taking advantage of the roof surface would significantly increase the profitability of investments. Promoting modern material solutions [3-5] will allow this form of producing cold in buildings to develop and be more available.

The work was realized within the allocation No. 0401/0007/17 awarded for Faculty of Environmental Engineering Wroclaw University of Science and Technology by Ministry of Science and Higher Education in years 2017-2018.

\section{References}

1. H. Nowak, Oddziaływanie cieplnego promieniowania środowiska zewnętrznego na budynek (Oficyna Wydawnicza Politechniki Wrocławskiej 1999)

2. H. Nowak, Zastosowanie badań termowizyjnych $w$ budownictwie (Oficyna Wydawnicza Politechniki Wrocławskiej 2012)

3. A. P. Raman, M. A. Anoma, L Zhu, E. Rephaeli, S. Fan, Nature, 515, pp. 540-544, 2014)

4. M. Hanif, T. M.I. Mahlia, A. Zare, T. J. Saksahdan, H. S.C. Metselaar, (Renew Sust Energ Rev, 32, 642-650, 2014)

5. L Zhu, A. Raman, S. Fan, (Proc. Natl. Acad. Sci. U. S. A., 112 (40), 12282-12287)

6. www.mib.gov.pl 